\title{
Practice and Thinking on the Construction of Teaching Psychological Environment Based on Positive Discipline
}

\author{
Wen $\mathrm{Hu}$ \\ Department of Psychology \\ Gannan Medical University \\ Ganzhou, China 341000
}

\author{
Xiaorong Gan \\ Department of Psychology \\ Gannan Medical University \\ Ganzhou, China 341000
}

\begin{abstract}
Different from the traditional behaviorism, positive discipline should reasonably and effectively use punishment and let students seek sense of belonging and selfvalue in social contexts. Teachers can make friendly contacts with students in mutual respect and focus on solving problems as well as explore reasons of students' behaviors, in order to truly help students to correct bad behaviors.
\end{abstract}

Keywords-positive discipline; psychological environment; punishment

\section{INTRODUCTION}

Students spend most of their learning time in the classroom. Effective learning environment can stimulate their learning interests and desire to explore knowledge. A good teaching environment is also of vital importance. The teaching psychological environment is a special psychological environment which obviously or potentially influences the teaching effect. In order to create good teaching psychological activities, we try to use positive discipline that teachers kindly help students to feel a sense of belonging and worth in mutual respect and encouragement, guide them to exploit potentialities and learn effective social and life skills from mistakes, proposing effective strategies in establishing harmonious teaching psychological environment.

\section{THE EFFECTIVE CRITICISM IS UNDERSTANDABLE AND REASONABLE SUCCESSIVELY}

In positive discipline, too strict or too mild teaching ways are inadvisable. It objects to blame, humiliation or physical and mental punishment. Criticism is a commonly-used method in schools to discipline students. Some students ignore while some mind teachers' criticism. Sometimes criticism fails to warn students or correct their behaviors especially for teenagers. Inappropriate criticism will make students dislike teachers or want to revenge even rebel. Some obey because of fear. In researching classroom psychology, Deng Yunlong finds $90.5 \%$ of students say they suffer from psychological hurt in class; $96.5 \%$ of students say they directly suffer from or see other students suffering from psychological abuse like discrimination, sarcasm, indifference and attack. In traditional educational concept, criticizing students in public is an education behavior to maintain classroom order, but inappropriate criticism ways greatly influence students' psychology and self-evaluation, making them feel they are worthless. According to Erickson's theory of social development, elementary school students and middle school students are in the periods of diligence feeling versus inferiority feeling (6,7 to 12 years old), role identity versus role confusion (12 to 18 years old) respectively. The two periods are important for the formation of self-consciousness. The authority of teachers makes the criticism and encouragement of them become distinctly important for students to form correct self-evaluation.

The traditional behavioral school directly tells students about their mistakes and how to do. But people with the opinion of positive discipline think we should invite students to think how to do. "Asking" is more effective than "telling" in psychological acceptance. When students make mistakes, we should first understand their behaviors. Understanding is not to support but to understand the reasons of their behaviors and their psychological process. Taking iceberg as an analogy, when problems appear, teachers often pay attention to the misconducts like the part of iceberg above water. Punishment can only solve the part above water namely the superficial problems. In fact, the purpose of students in making mistakes like iceberg below water is the deep-seated reason of students' misconducts. It is better for teachers to tell the similar feeling or experience of them for students in the communication. The criticism method that blames students cannot make them truly accept and they will not know about their mistakes. After showing empathy, teachers can express their opinions on problem behaviors, analyze reasons and results with students and then guide students to think better ways to solve problems. Teachers and students can reach a consensus or make rules. For example, some students lack concentration and chat with deskmate in class. Teachers can ask whether the student is tired and tell them it is normal that they cannot be concentrated all the time, and there are other ways to relax.

\section{MistaKes ARE GREAT LEARNING OPPORTUNITY}

Good classroom atmosphere can guarantee students' learning efficiency. Misconducts that obstruct the normal classroom discipline appear inevitably. It is caused by several 
students or most students. In positive discipline, teachers think it is normal for students to make mistakes, which are great opportunities to understand students and the class. Rudolf Dreikurs proposes mistake objective table which can help teachers to rapidly understand the reasons of students' behaviors like the part of iceberg below water and discipline and encourage effectively and reasonably.

When students have misconducts, teachers feel anger, worried and perturbed. They often remind and persuade but only can stop students for a little while. In reality, students hope to get special attention to feel their importance. Teachers can let students participate in a useful task and solving problems and transfer their behaviors, helping them to develop daily habits. For example, some students repeatedly break in the teacher in class and raise hand to loudly ask irrelevant problems after teachers stop them. Teachers can let them clean the blackboard or distribute exercise books to transfer their behaviors; in class meeting, let the student discuss how to do when students behave like this in class; let him supervise other students. In this way, it avoids the unpleasant punishment and meets students' requirements for excessive attention.

When students make mistakes, teachers feel anger, challenged and threatened. Students take passive resistance and feel they win when teachers anger. In fact, at this time, students refuse to be forced and think they have a sense of identity when the control power is in their hands. Teachers can transfer students' behaviors through letting them help and provide limited selection to withdraw from the conflict. For example, some students fail to obey the rules in queuing up, push other students and grab others' stationery and run counter to teachers. Teachers can ask him "can we discuss whether there are other ways to solve the problem?"

Some students are not confident and give up without try. They feel inferior to others and don't like to attract others' attention. In the end, they are regarded as inferior students. Teachers feel these students are helpless, desperate and care for nothing. In fact, these students think they are imperfect so they don't have a sense of belonging, feel helpless and give up on themselves, and they can never meet teachers' requirements. Teachers should stop the criticism, assign tasks in different steps and encourage them to try. Meanwhile, teachers should pay attention to students' merits, set an example instead of doing it for students. For example, some students are timid and asocial, seldom express their opinions. They are easily neglected by teachers. In fact, they need more attention of teachers because they don't have sense of belonging and recognition. Teachers can let them help other students in things in which they are adept and do things with others.

\section{TRANSFER THE OBJECTIVE FROM PUNISHMENT TO SEARCH FOR SOLUTIONS}

Positive discipline proposes $3 \mathrm{R} 1 \mathrm{H}$ in solving problems. 3R refers to Related, Respectful and Reasonable; $1 \mathrm{H}$ refers to Helpful. It means solutions favorable to problems should include the four elements. In the reflection of punitive measures, teachers should think whether it is related to the problem. Teachers and students should respect each other in behaviors and tone of voice. The solution to problem should be reasonable without punishment and make for students to do better. For example, some students don't do homework so teachers let them stand in the office. It is irrelevant to the homework; instead, it is respectful for teachers to ask students when they will complete it, giving students the right of choice. It is related to the correction of mistakes.

We can take four steps to solve problems. Firstly, ignore the problems. There is no need to solve problems in a hurry when it appears. We can temporarily weaken it and propose it in a respectful way, listen to the feelings and opinions of students or teachers. Secondly, we can find out the solution to problems agreed by both sides. Finally, problems can be solved in class meeting if it cannot be solved separately. (For example 1)

\section{GROUP GUIDANCE HELPS STUDENTS to ESTABLISH SENSE OF BELONGING AND WORTH}

According to scientific research, students have intense emotional connection with schools and contribute to more successful school education. Bao Kebing (2006) finds through research that students with strong sense of belonging to schools have higher school adaptive quality and self-evaluation. Compared to students in general schools, students in key schools have stronger sense of belonging to schools. The stronger sense of belonging can improve students' enthusiasm, degree of class participation and performance, at the same time reduce their misconducts. Sense of belonging refers to students' positive attachment to the school. For example, they feel they are a part of the class; realize teachers support and respect them; they have friends in school; believe the rules and regulations in school are equal, open and transparent. Teachers often think they treat students equally and considerately, but students cannot feel it. It shows teachers should improve ways to care for students.

Group guidance is frequently-used in psychological guidance. It makes individuals learn, observe, experience and carry out self-acceptance and strengthen cooperation through interaction of group (class) members. The hierarchy of needs theory proposed by humanistic psychologist Maslow emphasizes people have five needs of different levels. The needs for belonging and love are important. Healthy and harmonious psychological atmosphere in class can make members experience centralized sense of belonging and security right and willing to accept objectives and rules of the class. Group guidance in class can rapidly establish harmonious relationship, strengthen understanding and make for the establishment of sense of belonging to schools. It can get effect instantly in students' self-growth and construction of class atmosphere especially the establishment of class cohesiveness and sense of belonging; compared with traditional class meeting, group guidance is more popular among students.

Taking the class construction in the first year of junior high school as an example, they can take the following activities: ice-breaking activities (warm-up exercise) like snowball, cold wind blows and the tour of trust etc; "I want a family"- the leader ask several students to form a family, then these students hug each other. It lets students feel the warmth of 
organization and experience the feeling of being alone and the importance of actively accepting others; advantage bombing - compliment others sincerely, in order to let students appreciate others' shining points, better know about themselves through others' expression and feel collective support; two students bind one of their legs together to form three feet; tramcar; "cross mine field"- two students support each other to bypass the "land mines".

\section{CONCLUSION}

In the positive discipline, group guidance is applied to help students feel the sense of belonging and worth under mutual respect and encouragement. Punishment should be used reasonably to build harmonious teaching psychological environment.

\section{REFERENCES}

[1] Jane Nelson, Ltbb Lott, Positive Discipline in the Classroom [M], Beijing: Beijing Union Publishing, 2014

[2] Jing Xingshan. Give the Right of Classroom Management to Students [J], Journal of Teaching and Management, May 2016

[3] Bao Xia. Effective Application of Teachers' Right of Criticism-Based on Positive Discipline $[\mathrm{J}]$, Journal of Changchun University of Technology (Higher Education Research), 2013 (34).1

[4] Li Xin, Yang Yang. Discussion on Teaching Psychological Environment and Its Optimization Policy [J], Journal of Huaihua University, 2012 (31).1 